\title{
IFN- $\gamma-$, IL-4-, IL-17-, PD-1-Expressing T Cells and B Cells in Peripheral Blood from Tuberculosis Patients
}

\author{
Xiuyun $\mathrm{He}^{1^{*}}$, Xiangyu Huang ${ }^{1}$, Li Xiao ${ }^{1}$, Juan $\mathrm{Hao}^{1}, \mathrm{Jing} \mathrm{Li}^{2}$, Hongbing Chen ${ }^{2}, \mathrm{Yu} \mathrm{Gao}^{1}$, \\ Yazhen Zhao ${ }^{1}$, Chuanzhi Zhu ${ }^{1}$, Liqi Jiang ${ }^{1}$ \\ ${ }^{1}$ Central Laboratory, The $309^{\text {th }}$ Hospital of People's Liberation Army, Beijing, China \\ ${ }^{2}$ Tuberculosis Institute, The $309^{\text {th }}$ Hospital of People's Liberation Army, Beijing, China \\ Email: *xwhe@sohu.com
}

Received April 18, 2012; revised May 24, 2012; accepted June 9, 2012

\begin{abstract}
Although the efficacy of tuberculosis (TB) vaccines is tightly linked to cell-mediated immunity, some functions of T and B cells in TB patients remain unclear. To address how Mycobacterium tuberculosis infection inhibits $\mathrm{T}$ effector responses, we assessed the proportions of $\mathrm{T}$ cell subsets and B cells in peripheral blood from pulmonary TB (PTB) patients, pleural TB (PLTB) patients, and healthy subjects (HS, who showed purified protein derivative (PPD)-positive reactions) with flow cytometry. Compared to HS, PTB and PLTB patients exhibited higher proportions of B cells and Th17 cells, and lower proportions of Th2 cells and ratios of Th1 to Th17 cells and of Th2 to Th17 cells. PTB patients had higher $\mathrm{CD}^{+} \mathrm{T}$ cells and PD- $1^{+} \mathrm{CD}^{+} \mathrm{T}$ cells than HS. Newly diagnosed PTB patients (nPTB) had higher proportions of B cells than HS; in contrast, PTB patients subjected to effective treatments (oPTB) and HS shared similar proportions of B cells. oPTB patients had higher proportions of $\mathrm{CD}^{+} \mathrm{T}$ cells, Th17 cells, and PD- $1^{+} \mathrm{CD} 4^{+} \mathrm{T}$ cells than $\mathrm{HS}$, but this difference did not occur in nPTB patients. These findings suggest that shifting ratios of Th1 to Th17 cells may be beneficial for M. tuberculosis to amplify.
\end{abstract}

Keywords: Mycobacterium tuberculosis; B Cells; T Cells; Th Cells; PD-1

\section{Introduction}

Tuberculosis (TB), a serious infectious disease caused by Mycobacterium tuberculosis, is currently leading to the deaths of about 1.7 million people and also yielding millions of new TB cases per year [1]. Today available vaccines are able to induce long-lived antibody responses, but vaccines against intracellular organisms that require cell-mediated immunity (CMI) are neither available nor uniformly effective [2]. Mycobacterium bovis Bacille Calmette-Guérin (BCG) is a vaccine against $M$. tuberculosis, but it lacks longevity of protection and thus is not effective enough to stop TB spreading. Therefore it is needed to develop novel TB vaccines based on the mechanisms underlying protective immunity against $M$. tuberculosis.

CMI plays a pivotal role in controlling M. tuberculosis infection [3]. The cellular immune response to intracellular pathogens comprises a spectrum of T-cell subpopulations characterized by distinct cytokine secretion profiles and cell surface marker phenotypes [4]. $\mathrm{CD}^{+} \mathrm{T}$ cells have diverse Th effectors. For example, Th1, Th2, and Th17 cells are characterized by the production of

\footnotetext{
${ }^{*}$ Corresponding author.
}

different patterns of cytokines [5], and follicular helper CD4 T (Tfh) cells differ from Th1, Th2 or Th17 cells in gene expression and developmental regulation [6].

Th1 cells and Th17 cells play an important role in host defense against $M$. tuberculosis. Th1 cells produce IFN- $\gamma$ and regulate antigen presentation and immunity, which is a prerequisite for mounting efficient protection against $M$. tuberculosis [6,7]. For example, the induction of predominant Th1 responses by vaccine antigens has been observed in mice with reduced lung bacterial burden [8]. Compared to Th1 cells, Th17 cells show limited roles in controlling host defense against primary $M$. tuberculosis infection [9]. Th17 cells provide protective immune responses to M. tuberculosis through producing IL-17 and IL-21, or inducing the expression of CXCL9, CXCL10, and CXCL11 [10-12]. During the chronic TB phase, a shift of the response towards excessive IL-17 production may sustain extensive neutrophil recruitment and tissue damage [13]. Th1 and Th17 responses cross-regulate each other during infection, which may be important for the immunopathology of tuberculosis [12].

Th2 cells and Tfh cells can provide B cell help. Th2 cells produce IL-4, IL-5 and IL-13, and are essential for the generation of appropriate antibodies and the elimina- 
tion of extracellular pathogens [14]. Th2 cells are thought to exacerbate immunopathology during progressive TB and also may influence disease susceptibility [15]. B cell help is not solely attributable to Th2 cells as IL-4- and Stat6-deficient mice still make antibodies [16,17]. Tfh cells are specialized providers of B cell help and regulate $\mathrm{B}$ cell proliferation and immunoglobulin class-switching, particularly in the germinal center structures $[18,19]$. In this study Tfh cells in peripheral blood from TB patients were not assessed because their many markers are also found on activated cells [19].

Programmed death-1 (PD-1), a negative regulatory molecule on $\mathrm{T}$ cells, inhibits $\mathrm{T}$ and $\mathrm{B}$ cell activation when it binds to one of PD-1 ligand 1 and 2 (PD-L1 and PD-L2) in the context of antigen presentation [20]. PD-1 blockade can improve long-term survival and increase levels of tumor-reactive T cells [21]. PD-1/PD-L pathway plays a central role in the interaction between hosts and pathogenic microbes [22]. The BCG numbers in the spleen of PD-1-deficient mice were significantly reduced compared with wild-type mice [23]. However, PD-1deficient mice are extraordinarily sensitive to TB, showing that the PD-1 pathway is required to control M. tuberculosis infection $[24,25]$. Thus, it is needed to know whether and how PD-1 pathway induces protective immune responses or TB development during $M$. tuberculosis infection.

It is well known that humoral immunity, which is ascribed to the antibodies resulting from B cells, plays important roles in the elimination of extracellular pathogens. Detection of $M$. tuberculosis antigens-specific antibodies has been used to diagnose TB [26,27], but little is known about humoral immunity against $M$. tuberculosis.

Taken together, the functions of $\mathrm{B}$ cells and $\mathrm{T}$ cell subsets, determining host protection or pathology, are not completely understood during $M$. tuberculosis infection. TB patients provide an opportunity to explore the likely mechanisms of immune responses to M. tuberculosis infection. The purpose of this study was to examine the proportions of IFN- $\gamma$-, IL-4-, IL-17-, PD-1-expressing T cells and $\mathrm{B}$ cells in TB patients, deepening an understanding of immune responses to M. tuberculosis infection.

\section{Materials and Methods}

\subsection{Study Subjects}

TB patients and healthy subjects (HS) were recruited from the Tuberculosis Ward and Healthcare Center, the $309^{\text {th }}$ Hospital of the Chinese People's Liberation Army (PLA). All the participants were negative for human immunodeficiency virus (HIV). Mycobacterium tuberculosis infection causes pulmonary TB (PTB) mainly. Extra-pulmonary TB has many kinds such as pleural TB
(PLTB), tuberculous lymphadenitis, bone tuberculosis, and tuberculous meningitis; however, PLTB patients are common at the $309^{\text {th }}$ Hospital. Therefore PTB and PLTB patients were selected. PTB patients were identified according to the guidelines for PTB diagnosis and therapy authorized by the Tuberculosis Branch Association of the Chinese Medical Association, including clinical presentation, chest X-ray examination, Ziehl-Neelsen stained sputum smear, and mycobacterial culture. PLTB patients were identified according to clinical presentation and Ziehl-Nielsen stained- or mycobacterial culture-positive in pleural fluid. All PTB and PLTB patients showed appropriate responses to anti-tuberculosis chemotherapy. HS were recruited from those inoculated with BCG at birth and showed purified protein derivative (PPD)-positive $\left(\mathrm{PPD}^{+}\right)$reactions $(5-15 \mathrm{~mm})$. All participants were classified into three groups: 1) 22 PTB (13 males and nine females; aged 18 - 61 and mean age: 43.7), including 13 sputum culture- and smear-positive patients and nine sputum culture-positive patients, and 15 patients had $\mathrm{PPD}^{+}$reactions of $>10 \mathrm{~mm}$ and the remaining seven patients had no PPD skin test information; 2) 12 PLTB (eight males and four females; aged $17-53$ and mean age: 31.3); 3) 18 HS (six males and 12 females; aged 24 40 and mean age: 31.2 ). PTB patients were further divided three subgroups: 1) Nine newly diagnosed PTB patients (nPTB), whose specimens were collected within one week after anti-TB treatment, 2) Five PTB patients who leaved hospital within three days after collecting specimens (oPTB), and 3) Eight PTB patients who were subjected to 3 - 6-month anti-TB treatment before collecting specimens and continued treatment for no less than two months after collecting specimens (cPTB). Approval was granted by the ethics committee of the $309^{\text {th }}$ Hospital, PLA, and all participants provided informed consent.

\subsection{Flow Cytometry}

Two milliliters of heparinized peripheral blood was harvested and used for flow cytometry (FCM) analysis. For $\mathrm{B}$ cells, $\mathrm{CD}^{+} \mathrm{T}$ cells, $\mathrm{CD}^{+} \mathrm{T}$ cells, and $\mathrm{CD} 8^{+} \mathrm{T}$ cells analyses, $100 \mu \mathrm{L}$ of fresh blood was incubated for $30 \mathrm{~min}$ at room temperature (RT) with $20 \mu \mathrm{L}$ A reagent of $\mathrm{T} / \mathrm{B} / \mathrm{NK}$ kit (BD Biosciences) including anti-CD3-fluorescein isothiocyanate (FITC), anti-CD4-allophycocyanin (APC), anti-CD8-Phycoerythrin (PE), and antiCD45-peridinin chlorophyll protein (PerCP). $100 \mu \mathrm{L}$ of fresh blood was incubated for 30 min at RT with $20 \mu \mathrm{L}$ B reagent of T/B/NK kit including anti-CD3-FITC, antiCD19-APC, anti-CD45-PerCP, and anti-CD16CD56-PE. Erythrocytes were lysed by adding $2 \mathrm{~mL} 1 \mathrm{X}$ FACS Lysing Solution (BD Biosciences). The cells were washed with PBS before FCM analysis. 
For Th1, Th2, and Th17 cell analyses, $500 \mu \mathrm{L}$ of fresh blood diluted 1:1 with RPMI 1640 (Gibco) in FCM tubes with cap was stimulated with Phorbol 12-myristate 13acetate $(25 \mathrm{ng} / \mathrm{mL}$ final concentration, Sigma) and ionomycin $(1 \mu \mathrm{g} / \mathrm{mL}$ final concentration, Sigma) in the presence of brefeldin-A (BFA, $10 \mu \mathrm{g} / \mathrm{mL}$ final concentration, Sigma) for $5 \mathrm{~h}$ at $37^{\circ} \mathrm{C}$. $200 \mu \mathrm{L}$ stimulated cells were incubated with anti-CD3-PerCP and anti-CD8-APC for $15 \mathrm{~min}$ at RT. Erythrocytes were lysed by adding $2 \mathrm{ml}$ 1X FACS Lysing Solution (BD Biosciences) for $10 \mathrm{~min}$ at RT. After centrifugation, the cells were washed with cold PBS, resuspended in Fix/Perm buffer (eBio-science), and left for $30 \mathrm{~min}$ at $4{ }^{\circ} \mathrm{C}$. After blocking with $2 \%$ rat serum in Permeabil buffer (eBioscience) for $15 \mathrm{~min}$ at $4^{\circ} \mathrm{C}$, the cells were incubated for $15 \mathrm{~min}$ at RT with one of the following antibodies conjugated with fluorescence, i.e. anti-IFN- $\gamma$-FITC, anti-IL-4-PE, anti-IL-17A-PE, or isotype control mouse IgG1-PE (BD Biosciences). The cells were washed and fixed in 1\% parafor-maldehyde.

For PD-1-expressing T cells analyses, $100 \mu \mathrm{L}$ of fresh blood was incubated for $30 \mathrm{~min}$ at RT with antibodies conjugated with fluorescence, including anti-CD3-PerCP, anti-CD8-APC, and anti-PD-1-PE (BD Biosciences). Erythrocytes were lysed by adding $2 \mathrm{~mL} 1 \mathrm{X}$ FACS Lysing Solution (BD Biosciences). The cells were washed with PBS before FCM analysis.

The above-stained cells were analyzed with a 4-colour FACSCalibur flow cytometer (BD Biosciences). Lymphocytes were acquired by FCM forward side scatter gating. The percentage of positive cells and the mean fluorescence intensity (arbitrary units) for a specific marker were calculated using CellQuest software (version 3.3, BD Biosciences). The percentage of IFN- $\gamma-$, IL-4-, IL-17- and PD-1-producing $\mathrm{CD}^{+}{ }^{+} \mathrm{T}$ cells was equal to the percentage of IFN- $\gamma^{+}, \mathrm{IL}-4^{+}, \mathrm{IL}-17^{+}$and $\mathrm{PD}-1^{+} \mathrm{CD} 8^{-} \mathrm{T}$ cells in this study, respectively.

\subsection{Data Analyses}

The data were presented as means +1 SE. One-way analysis of variance with LSD comparisons was used to compare means among different groups at $p<0.05$. All statistic analyses were carried out using SPSS 13.0.

\section{Results}

\subsection{Increased Percentages of $B$ Cells in TB Patients}

PTB and PLTB patients had a higher percentage of $\mathrm{CD}^{-}$ CD19 $9^{+}$lymphocyte (B cells) than HS ( $p=0.0003$ and $p=$ 0.049 ), and there was no difference in the percentage of B cells between PTB and PLTB patients $(p>0.05)$ (Figure 1(a)). nPTB and $\mathrm{CPTB}$ patients had a higher percentage of B cells than HS ( $p=0.000$ and $p=0.001)$, and oPTB patients exhibited similar percentages of B cells with nPTB patients, cPTB patients, and HS (all $p>0.05$ )
(Figure 1(b)).

\subsection{Increased Percentages of $\mathrm{CD}^{+} \mathrm{T}$ Cells and Decreased Percentages of $\mathrm{CDB}^{+} \mathrm{T}$ Cells in PTB Patients}

PTB patients, PLTB patients, and HS shared similar frequencies of $\mathrm{CD}^{+} \mathrm{T}$ cells (all $p>0.05$ ); PTB patients had

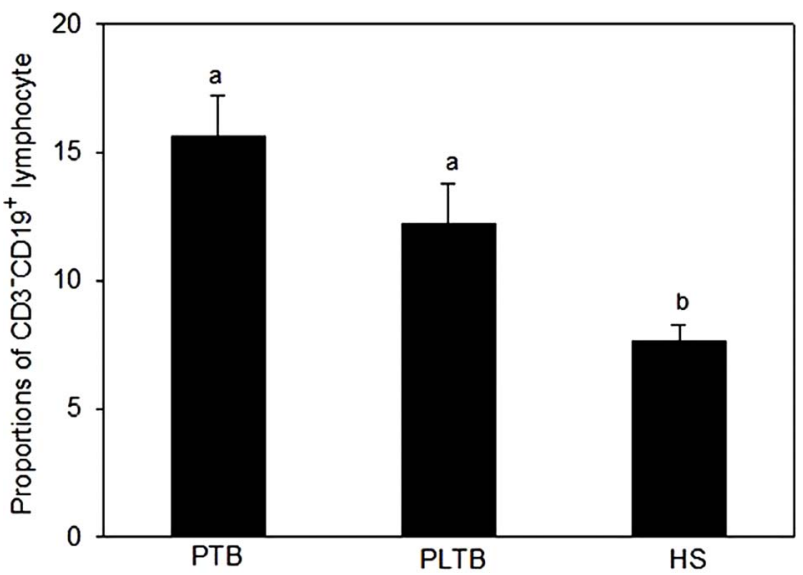

(a)

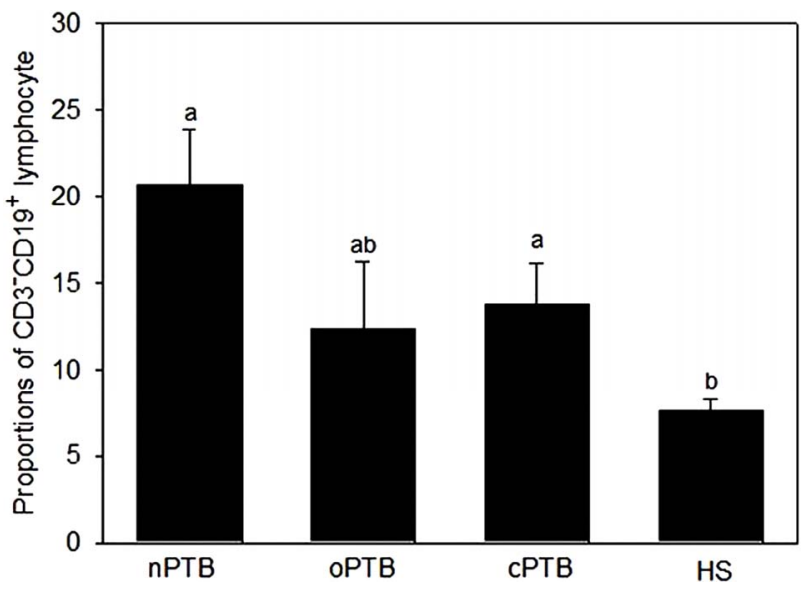

(b)

Figure 1. Comparisons of the proportions of $\mathrm{CD3}^{-} \mathrm{CD}^{+}$ lymphocyte (B cells) in peripheral blood from TB patients and healthy subjects (HS). (a) The proportions of B cells in peripheral blood from patients with pulmonary tuberculosis (PTB), patients with pleural tuberculosis (PLTB), and HS; (b) The proportions of $B$ cells in peripheral blood from nPTB, oPTB, cPTB, and HS. Data are means + 1 SE. Oneway analysis of variance with LSD comparisons was used to compare means among different groups. The bars followed by different letters are significantly different at $p=0.05$ or $p$ $=0.01$ while the bars followed by same letter are not significantly different at $p=0.05$. nPTB: Newly diagnosed PTB patients whose specimens were collected within one week after treatment; oPTB: PTB patients who leaved hospital within three days after collecting specimens, cPTB: PTB patients who were subjected to 3 - 6-month treatment before collecting specimens and continued treatment for no less than two months after collecting specimens. 
a higher percentage of $\mathrm{CD}^{+} \mathrm{T}$ cells and a lower percentage of $\mathrm{CD}^{+} \mathrm{T}$ cells than $\mathrm{HS}(p=0.004$ and $p=$ $0.048)$; PLTB patients exhibited a higher percentage of $\mathrm{CD}^{+} \mathrm{T}$ cells than HS $(p=0.016)$, and shared similar percentages of $\mathrm{CD}^{+} \mathrm{T}$ cells with PTB patients and similar percentages of $\mathrm{CD}^{+} \mathrm{T}$ cells with PTB patients and HS (all $p>0.05$ ) (Figure 2(a)).

There were no differences in the proportions of $\mathrm{CD}^{+}$ T cells among $\mathrm{nPTB}$, oPTB, cPTB patients, and HS (all $p$ $>0.05$ ) (data not shown). nPTB and oPTB patients had higher percentages of CD $4^{+} \mathrm{T}$ cells than $\mathrm{HS}(p=0.040$ and $p=0.027)$, and this phenomenon did not appear in nPTB, oPTB, and cPTB patients (all $p>0.05$ ); oPTB patients

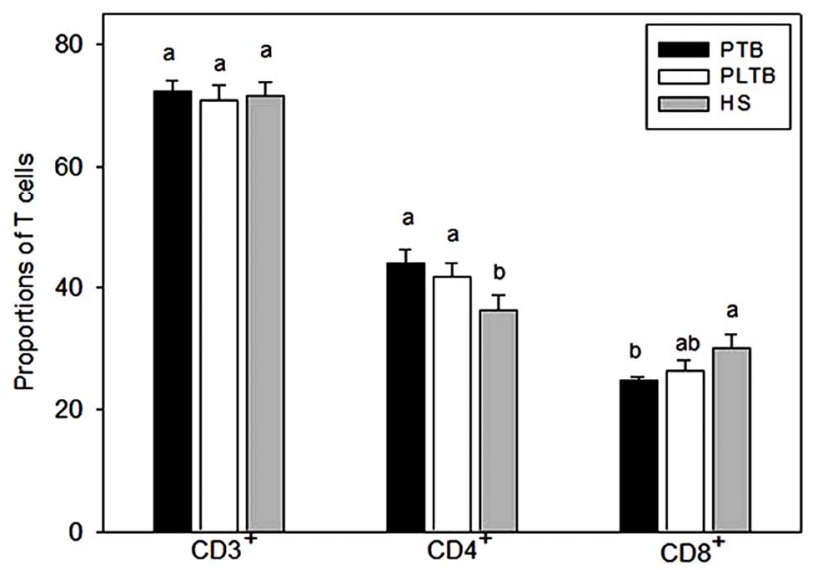

(a)

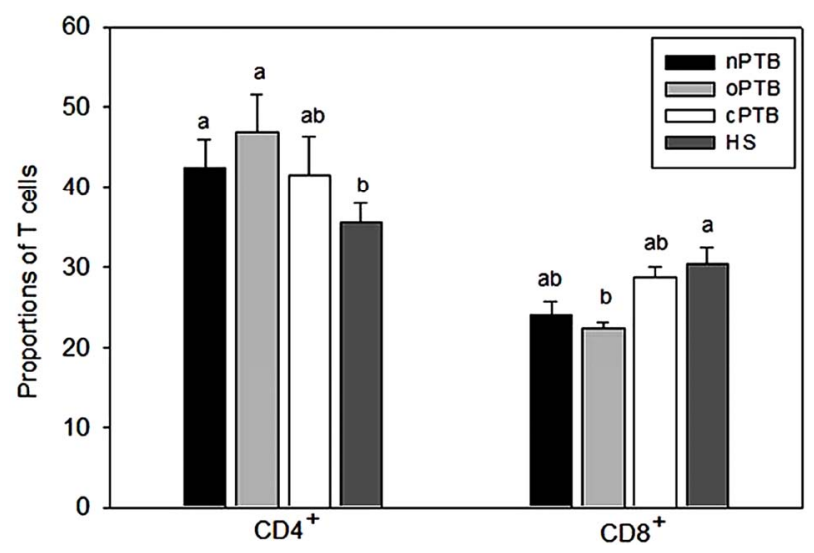

(b)

Figure 2. Comparisons of the proportions of $T$ cells in peripheral blood from TB patients and healthy subjects (HS). A The proportions of $\mathrm{CD3}^{+}, \mathrm{CD4}^{+}$, and $\mathrm{CD8}^{+} \mathrm{T}$ cells in peripheral blood from PTB patients, PLTB patients, and HS. $\mathrm{B}$ The proportions of $\mathrm{CD4}^{+}$and $\mathrm{CD8}^{+} \mathrm{T}$ cells in peripheral blood from nPTB, oPTB, cPTB, and HS. Data are means + 1 SE. One-way analysis of variance with LSD comparisons was used to compare means of the same kind of $T$ cells among different groups. The bars followed by different letters are significantly different at $p=0.05$ or $p=0.01$ while the bars followed by same letter are not significantly different at $p=0.05$. PTB, PLTB, nPTB, oPTB, and cPTB are coded as in Figure 1. had a lower percentage of $\mathrm{CD} 8^{+} \mathrm{T}$ cells than HS $(p=0.037)$ whereas nPTB patients, cPTB patients, and HS shared similar percentages of $\mathrm{CD}^{+} \mathrm{T}$ cells (Figure 2(b)).

\subsection{Increased Percentages of Th17 Cells and Decreased Percentages of Th2 Cells in TB Patients}

The percentages of IFN- $\gamma$-, IL-4-, and IL-17-producing $\mathrm{CD}^{+} \mathrm{T}$ cells (i.e. Th1, Th2 and Th17 cells) were nearly equal to those of IFN- $\gamma^{+}, \mathrm{IL}-4^{+}$, and IL- $17^{+} \mathrm{CD} 8^{-} \mathrm{T}$ cells on the basis of FCM analysis, respectively (Figure 3(a)). There were no differences in the proportions of Th1 cells among PTB patients, PLTB patients, and HS (Figure 3(b); all $p>0.05$ ). PTB and PLTB patients had lower Th2 cells and higher Th17 cells than HS (Figure 3(b); $p$ $=0.0017$ and $p=0.009$ for Th2 cells; $p=0.0048$ and $p=$ 0.026 for Th17 cells). PTB patients and PLTB patients shared similar frequencies of Th2 and Th17 cells (Figure 3(b); all $p>0.05$ ). PTB patients had lower IL-4- and IL-17-producing $\mathrm{CD} 8^{+} \mathrm{T}$ cells (IL-4 $4^{+} \mathrm{CD} 8^{+} \mathrm{T}$ cells and $\mathrm{IL}-17^{+} \mathrm{CD} 8^{+} \mathrm{T}$ cells $)$ than $\mathrm{HS}(p<0.001$ and $p=0.047)$, PLTB patients had lower IFN- $\gamma$-producing $\mathrm{CD} 8^{+} \mathrm{T}$ cells (IFN- $\gamma^{+} \mathrm{CD} 8^{+} \mathrm{T}$ cells) and IL- $4^{+} \mathrm{CD} 8^{+} \mathrm{T}$ cells than $\mathrm{HS}(p$ $=0.002$ and $p<0.001$ ), and the percentage of IFN- $\gamma^{+}$ $\mathrm{CD} 8^{+} \mathrm{T}$ cells was higher in PTB patients than in PLTB patients $(p=0.034)$ (Figure 3(c)).

There were no differences in the proportions of Th1 and Th2 cells among nPTB, oPTB, cPTB, and HS (Figure 4; all $p>0.05$ ). oPTB and $\mathrm{CPTB}$ patients had higher percentages of Th17 cells than HS $(p=0.025$ and $p=$ 0.032 ), and this phenomenon was not detected in $\mathrm{nPTB}$ patients $(p>0.05)$ (Figure 4). oPTB patients had a higher percentage of Th17 cells than nPTB patients ( $p=$ 0.027), and there were no differences in the percentage of Th17 cells between cPTB and both nPTB and oPTB (all $p>0.05$ ) (Figure 4).

The ratios of Th1 cells to Th2 cells were higher in PTB patients than in HS $(2.89 \pm 0.44$ vs $1.45 \pm 0.12, p=$ 0.006 ), and PLTB patients and HS shared similar ratios of Th1 cells to Th2 cells $(2.19 \pm 0.38$ vs $1.45 \pm 0.12, p=$ 0.22). The ratios of Th1 cells to Th17 cells and of Th2 cells to Th17 cells were lower in PTB and PLTB patients than in HS $(p=0.033$ and $p=0.046$ for Th1:Th17, $p=$ 0.009 and $p=0.029$ for Th2:Th17).

\subsection{Increased Percentages of PD-1-Expressing $\mathrm{CD4}^{+} \mathrm{T}$ Cells in PTB Patients}

The percentage of PD-1-expressing $\mathrm{CD} 4^{+} \mathrm{T}$ cells $\left(\mathrm{PD}-1^{+}\right.$ $\mathrm{CD} 4^{+} \mathrm{T}$ cells) was higher in PTB patients than in $\mathrm{HS}(p=$ 0.009); PLTB patients and HS shared similar percentages of PD $-1^{+} \mathrm{CD}^{+} \mathrm{T}$ cells $(p=0.087)$; there were no differences in the percentage of $\mathrm{PD}-1^{+} \mathrm{CD} 8^{+} \mathrm{T}$ cells among 
PTB patients, PLTB patients, and HS (all $p>0.05$ ) (Figure 5(a)). oPTB patients had a higher percentage of $\mathrm{PD}-1^{+} \mathrm{CD} 4^{+} \mathrm{T}$ cells than $\mathrm{nPTB}$ patients and $\mathrm{HS}(p=$ 0.014 and $p=0.000)$, the percentage of $\mathrm{PD}-1^{+} \mathrm{CD} 4^{+} \mathrm{T}$ cells was higher in cPTB patients than in HS $(p=0.011)$, this difference was not found between nPTB patients and both cPTB patients and HS (all $p>0.05$ ) (Figure 5(b)). There were no differences in the percentage of PD- $1^{+}$ $\mathrm{CD} 8^{+} \mathrm{T}$ cells between $\mathrm{nPTB}$, oPTB, $\mathrm{cPTB}$, and $\mathrm{HS}$ (all $p$ $>0.05$ ) (data not shown).



CD8 APC
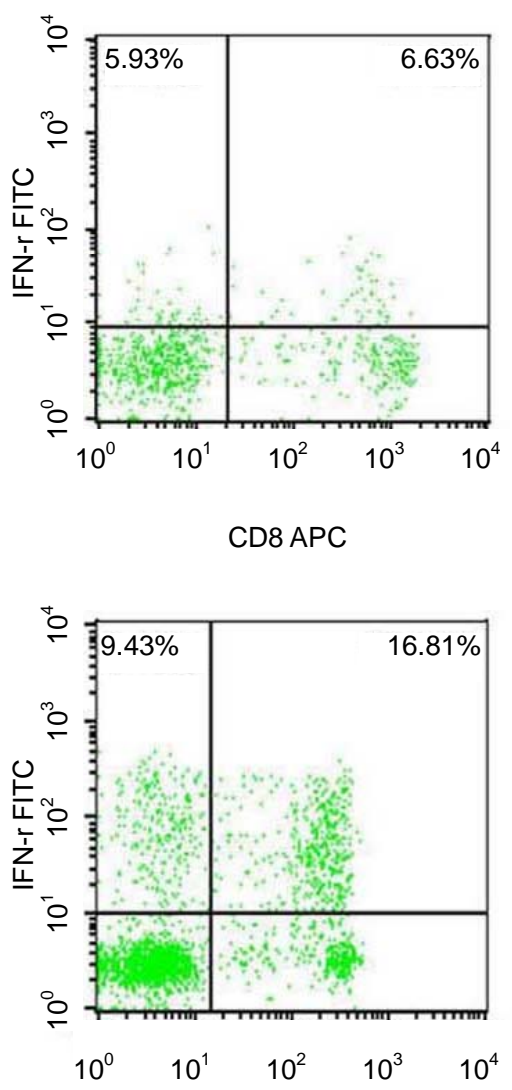

CD8 APC

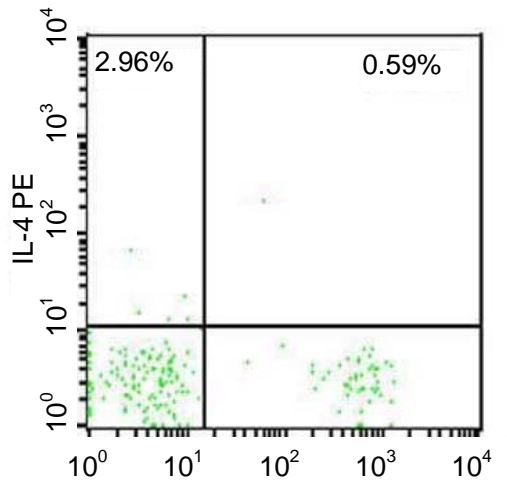

CD8 APC
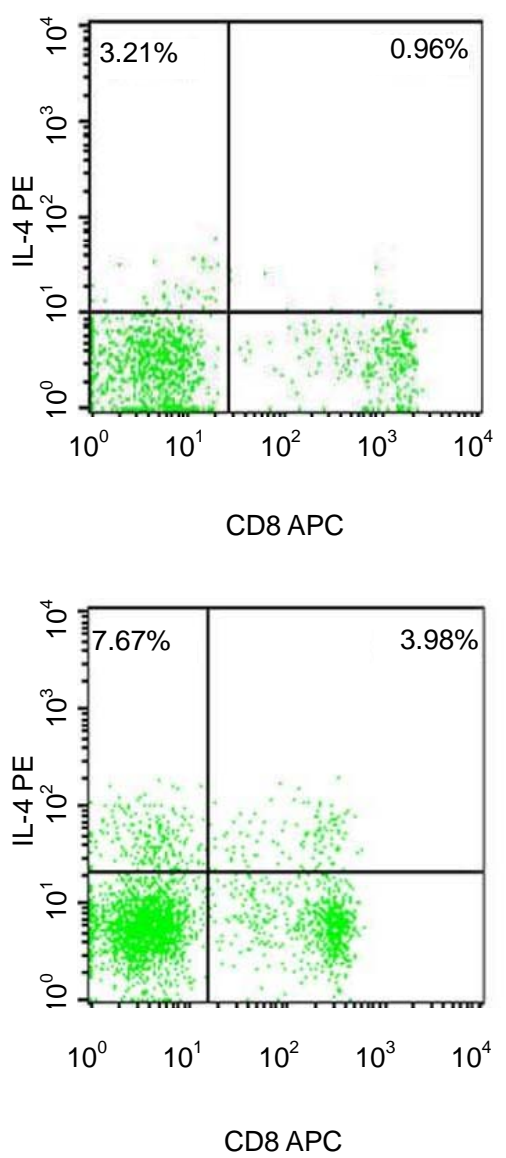

(a)
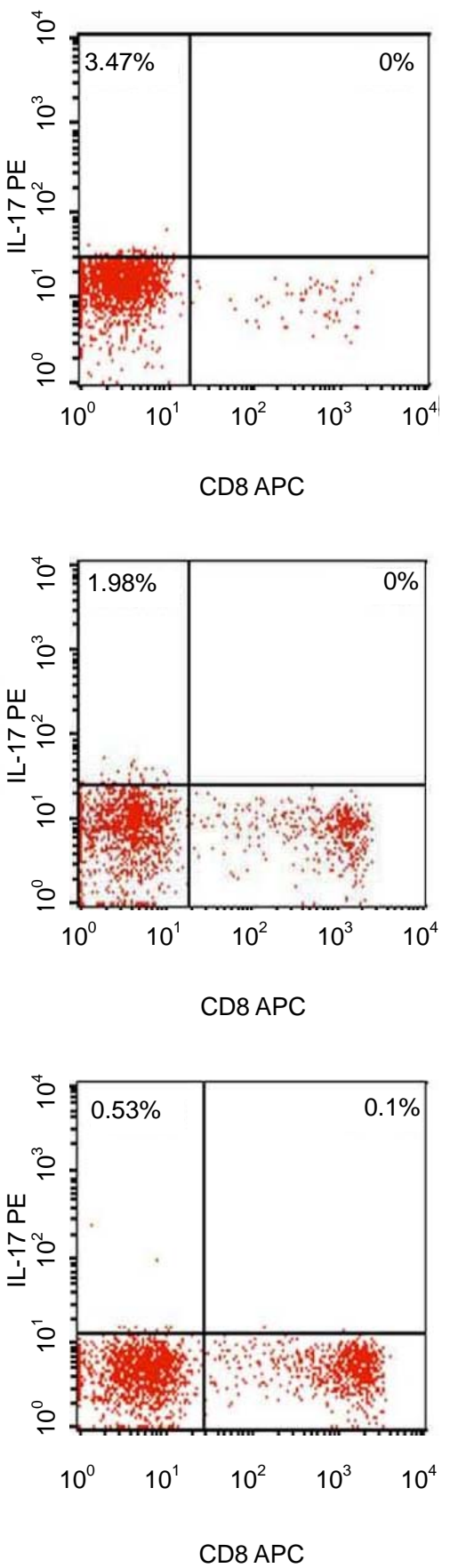

CD8 APC 


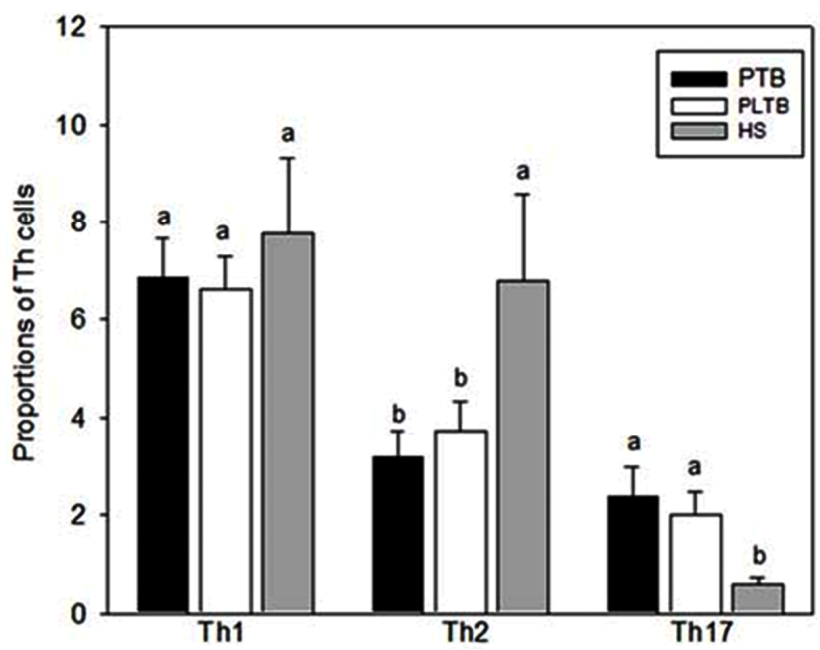

(b)



(c)

Figure 3. The proportions of IFN- $\gamma$-, IL-4-, and IL-17-producing T cells in peripheral blood from PTB patients, PLTB patients, and HS. A representative flow cytometry pattern of IFN- $\gamma$-, IL-4-, and IL-17-producing $\mathrm{CD8}^{-}$and $\mathrm{CDB}^{+} \mathrm{T}^{\mathrm{cells}}$. IFN- $\gamma^{+}$ CD8-, IL-4 ${ }^{+} \mathrm{CD8}^{-}$, and $\mathrm{IL}_{-17^{+}} \mathrm{CD8}^{-} \mathrm{T}$ cells represented Th1, Th2, and Th17 cells, respectively. B Comparisons of the proportions of Th1, Th2, and Th17 cells. C Comparisons of the proportions of IFN- $\gamma$-, IL-4-, and IL-17-producing CD8 ${ }^{+}$T cells. For panels $B$ and $C$, data are means +1 SE. One-way analysis of variance with LSD comparisons was used to compare means of the same kind of Th cells among different groups. The bars followed by different letters are significantly different at $p=0.05$ or $p=0.01$ while the bars followed by same letter are not significantly different at $p=0.05$. PTB, PLTB, and HS are coded as in Figure 1.

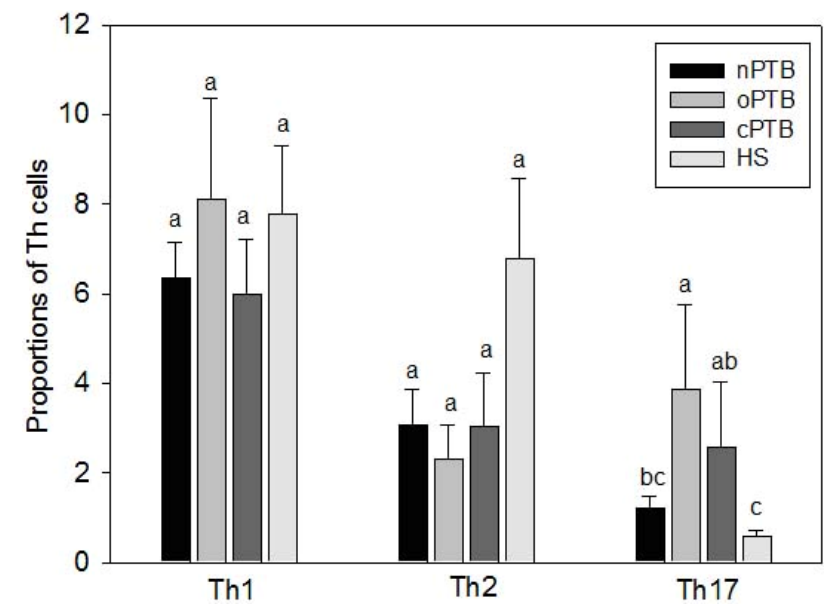

Figure 4. Comparisons of the percentages of Th1, Th2, and Th17 cells in peripheral blood from nPTB, oPTB, cPTB, and HS. Data are means $+1 \mathrm{SE}$. One-way analysis of variance with LSD comparisons was used to compare means of the same kind of $T h$ cells among different groups. The bars followed by different letters are significantly different at $p=$ 0.05 or $p=0.01$ while the bars followed by same letter are not significantly different at $p=0.05$. nPTB, oPTB, cPTB, and $H S$ are coded as in Figure 1.

crease in B cells at the end of the treatment [28]. PTB patients had higher Th17 cells and PD- $1^{+} \mathrm{CD} 4^{+} \mathrm{T}$ cells, which can be primarily attributed to oPTB and $\mathrm{CPTB}$ patients. There was no difference in Th17 cells and PD- $1^{+} \mathrm{CD} 4^{+} \mathrm{T}$ cells between $\mathrm{nPTB}$ patients and HS. These results suggest that anti-TB treatment may de- crease the proportion of $\mathrm{B}$ cells and increase the proportions of Th17 cells and PD- $1^{+} \mathrm{CD} 4^{+} \mathrm{T}$ cells in PTB patients.

Activated Th1 and Th17 cells provide protection against M. tuberculosis [29]. It is well known that Th1 cells and IFN- $\gamma$ are crucial for protection against $M$. tuberculosis [30-32], and PTB patients have a decreased percentage of Th1 cells [33]. Adoptive transfer of Th17 CD4 T cells specific for ESAT-6 can partially inhibit $M$. tuberculosis growth [34]. A high dose of MVA85A, a candidate TB vaccine, can elicit high levels of Th1 and Th17 cells, and Th17 cells are detected later than Th1 cells and are of a low magnitude [35]. BCG-specific Th17 cells can provide IFN- $\gamma$-independent protection against M. tuberculosis, and low-frequency Th17 cells can recruit Th1 cells to the lung for providing immune protection against $M$. tuberculosis $[9,36]$. Multidrug resistant (MDR) M. tuberculosis strains can induce stronger IL-17 than drug-susceptible strains in vitro and MDR-TB patients show high IL-17 expression [37]. We found that the percentage of Th1 cells did not signifycantly decrease in TB patients, but the percentage of Th17 cells increased in TB patients, yielding lower ratios of Th1 cells to Th17 cells. Our findings are consistent with Wang et al. [38], but inconsistent with Chen et al. [39], who found that the frequency of Th17 cells was lower in patients with tuberculous meningitis. These results, combined with other studies, indicate that lowfrequency Th17 cells may be helpful to protect against 


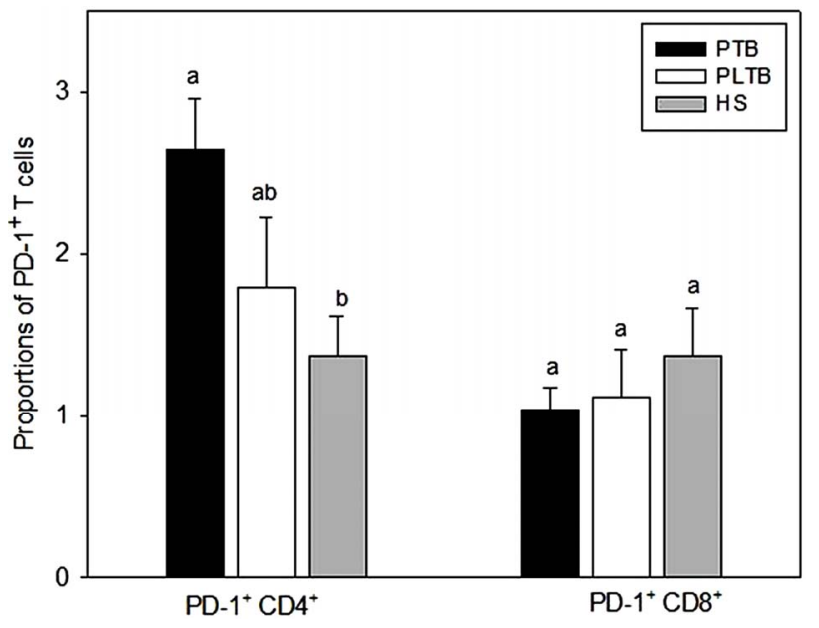

(a)

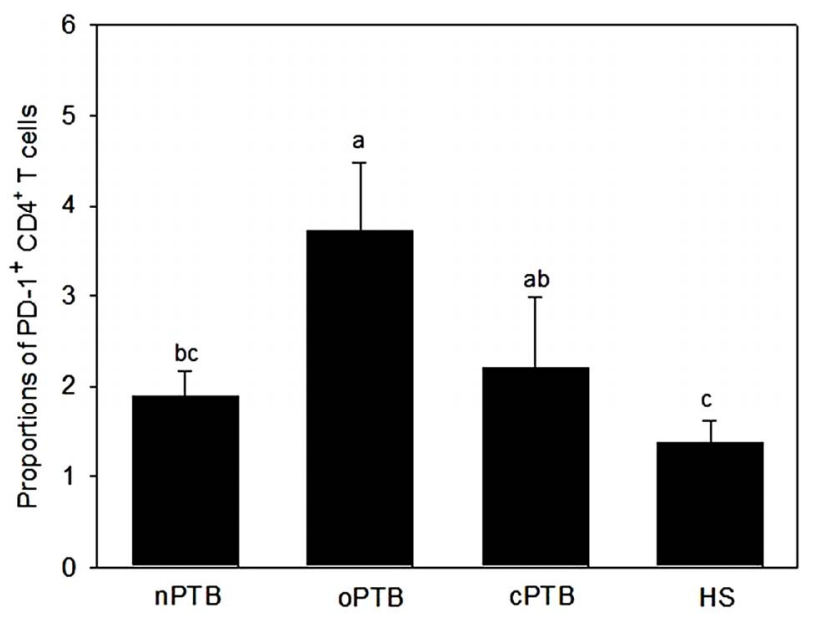

(b)

Figure 5. Comparisons of the proportions of PD-1-expressing $T$ cells in peripheral blood from TB patients and healthy subjects (HS). A The proportions of PD-1-producing $\mathrm{CD4}^{+}$and $\mathrm{CD8}^{+} \mathrm{T}$ cells in peripheral blood from PTB patients, PLTB patients, and HS. B The proportions of PD-1-producing $\mathrm{CD4}^{+} \mathrm{T}$ cells in peripheral blood from nPTB, oPTB, cPTB, and HS. Data are means + 1 SE. Oneway analysis of variance with LSD comparisons was used to compare means of the same kind of $\mathrm{PD}-\mathrm{1}^{+} \mathrm{T}$ cells among different groups. The bars followed by different letters are significantly different at $p=0.05$ or $p=0.01$ while the bars followed by same letter are not significantly different at $p=$ 0.05. PTB, PLTB, HS, nPTB, oPTB, and CPTB are coded as in Figure 1.

M. tuberculosis and that high-frequency Th17 cells and low ratios of Th1 cells to Th17 cells may induce immunopa- thogenesis.

$\mathrm{Th} 2$ cells can regulate humoral response. Increased Th2 responses have been postulated to play a role in susceptibility to TB, as IL-4 and IL-13 can undermine Th1-mediated immunity and drive inappropriate alternative activation of macrophages [40,41]. Previous studies suggest that TB patients have higher Th2 cells [42] and diabetic TB patients susceptible to TB partially come from a higher Th2 bias [43]. The ratios of Th1 cells to Th2 cells were higher and the proportion of Th2 cells and ratios of Th2 cells to Th17 cells were lower in peripheral blood from PTB patients, suggesting that the dynamic balance of Th1, Th2 and Th17 cells may influence the outcome of $M$. tuberculosis infection.

PD-1 belongs to co-inhibitory molecules. Some studies show that PD-1 plays inhibitory roles in M. tuberculosis infection. For example, blockage of PD-1 or PD-1/PDLs enhances the specific degranulation of $\mathrm{CD} 8^{+} \mathrm{T}$ cells and percentages of specific IFN- $\gamma$-producing lymphocytes against $M$. tuberculosis $[25,44]$. By contrast, other studies show that PD-1 promotes mycobacterial clearance in mice $[24,45]$, and host resistance to $M$. tuberculosis requires inhibition by PD-1 to prevent $\mathrm{T}$ cell-driven exacerbation of the infection [46]. Due to expression by neutrophils, PD-L1 usually increases in whole blood from active TB patients [47]. The proportion of PD- $1^{+} \mathrm{CD} 4^{+} \mathrm{T}$ cells was higher in PTB patients than in HS so that we propose a hypothesis that neutrophils accumulate in situations of high $M$. tuberculosis load accompanied with $\mathrm{CD}^{+} \mathrm{T}$ cells accumulation through interactions between PD-1 on $\mathrm{CD}^{+} \mathrm{T}$ cells and PD-L1 on neutrophils in peripheral blood from $\mathrm{TB}$ patients, thereby contributing to pathology.

Although CMI has always been become the focus of TB vaccine designs, antibody responses are also essential to contain mycobacterial infection $[3,48,49]$. To date there are contrasting findings in terms of the proportion of B cells in TB patients. For example, some studies suggest that the percentages of B cells are lower in TB patients than in HS $[28,50]$. Other studies indicates that the percentage of $\mathrm{B}$ cells is either higher or similar between PTB patients and HS [51,52]. In our study PTB and PLTB patients had a higher proportion of B cells than HS. Current development and evaluation of vaccines that induce both CMI and humoral immunity is a clear testimony to paradigm shifts and a new era for TB vaccines [3].

In conclusion, PTB patients had higher percentages of $\mathrm{B}$ cells, Th17 cells, PD- $1^{+} \mathrm{CD} 4^{+} \mathrm{T}$ cells and lower percentages of Th2 cells and ratios of Th1 cells to Th17 cells and of Th2 cells to Th17 cells. These findings suggest that the dynamic balance between proportions of T-cell subpopulations and negative regulatory molecules on $\mathrm{T}$ cells appears to play important roles in providing immune protection against $M$. tuberculosis, but this balance may be broken during $M$. tuberculosis infection. On the other hand, the roles of B cells, T-cell subpopulations, and PD-1 on T cells may be intricate during $M$. tuberculosis infection, and further studies with more TB cases are required to elucidate the possible mechanisms underlying cellular protective immunity. 


\section{Acknowledgements}

This study was funded by grants from the Ministry of Science and Technology of China (2006AA02Z465) and National Key Infectious Disease Project (2008ZX10003009).

\section{REFERENCES}

[1] World Health Organization, "Global Tuberculosis Control," WHO Report, 2010. http://www.who.int/tb/publications/global-report/2010/en /index.html

[2] S. Gurunathan, D. M. Klinman and R. A. Seder, "DNA Vaccines: Immunology, Application, and Optimization," Annual Review of Immunology, Vol. 18, 2000, pp. 927974. doi:10.1146/annurev.immunol.18.1.927

[3] F. Abebe and G. Bjune, "The Protective Role of Antibody Responses during Mycobacterium tuberculosis Infection," Clinical \& Experimental Immunology, Vol. 57, No. 2, 2009, pp. 235-243. doi:10.1111/j.1365-2249.2009.03967.x

[4] U. Sester, M. Fousse, J. Dirks, U. Mack, A. Prasse, M. Singh, A. Lalvani and M. Sester, "Whole-Blood FlowCytometric Analysis of Antigen-Specific CD4 T-Cell Cytokine Profiles Distinguishes Active Tuberculosis from Non-Active States," PLoS One, Vol. 6, No. 3, 2011, Article ID: e17813. doi:10.1371/journal.pone.0017813

[5] L. E. Harrington, R. D. Hatton, P. R. Mangan, H. Turner, T. L. Murphy, K. M. Murphy and C. T. Weaver, "Interleukin 17-Producing CD4 ${ }^{+}$Effector T Cells Develop via a Lineage Distinct from the T Helper Type 1 and 2 Lineages," Nature Immunology, Vol. 6, No. 11, 2005, pp. 1123-1132. doi:10.1038/ni1254

[6] R. I. Nurieva, Y. Chung, D. Hwang, X. O. Yang, H. S. Kang, L. Ma, Y. H. Wang, S. S. Watowich, A. M. Jetten, Q. Tian and C. Dong, "Generation of T Follicular Helper Cells Is Mediated by Interleukin-21 but Independent of T Helper 1, 2, or 17 Cell Lineages," Immunity, Vol. 29, No. 1, 2008, pp. 138-149. doi:10.1016/j.immuni.2008.05.009

[7] D. Young and C. Dye, "The Development and Impact of Tuberculosis Vaccines," Cell, Vol. 124, No. 4, pp. 683687. doi:10.1016/j.cell.2006.02.013

[8] S. Bertholet, G. C. Ireton, M. Kahn, J. Guderian, R. Mohamath, N. Stride, E. M. Laughlin, S. L. Baldwin, T. S. Vedvick, R. N. Coler and S. G. Reed, "Identification of Human T Cell Antigens for the Development of Vaccines against Mycobacterium tuberculosis," The Journal of Immunology, Vol. 181, No. 11, 2008, pp. 7948-7957.

[9] S. J. Aujla, P. J. Dubin and J. K. Kolls, "Th17 Cells and Mucosal Host Defense," Seminars in Immunology, Vol. 19, No. 6, 2007, pp. 377-382. doi:10.1016/j.smim.2007.10.009

[10] E. Bettelli, T. Korn and V. K. Kuchroo, "Th17: The Third Member of the Effector T Cell Trilogy," Current Opinion in Immunology, Vol. 19, No. 6, 2007, pp. 652-657. doi:10.1016/j.coi.2007.07.020

[11] S. A. Khader, G. K. Bell, J. E. Pearl, J. J. Fountain, J. Rangel-Moreno, G. E. Cilley, F. Shen, S. M. Eaton, S. L.
Gaffen, S. L. Swain, R. M. Locksley, L. Haynes, T. D. Randall and A. M. Cooper, "IL-23 and IL-17 in the Establishment of Protective Pulmonary $\mathrm{CD}^{+} \mathrm{T}$ Cell Responses after Vaccination and during Mycobacterium tuberculosis Challenge," Nature Immunology, Vol. 18, No. 4, 2007, pp. 369-377.

[12] S. A. Khader and A. M. Cooper, "IL-23 and IL-17 in Tuberculosis," Cytokine, Vol. 41, No. 2, 2008, pp. 79-83. doi:10.1016/i.cyto.2007.11.022

[13] E. Torrado and A. M. Cooper, "IL-17 and Th17 Cells in Tuberculosis," Cytokine \& Growth Factor Reviews, Vol. 21, No. 6, 2010, pp. 455-462. doi:10.1016/j.cytogfr.2010.10.004

[14] T. R. Mosmann and R. L. Coffman, "TH1 and TH2 Cells: Different Patterns of Lymphokine Secretion Lead to Different Functional Properties," Annual Review of Immunology, Vol. 7, 1989, pp. 145-173. doi:10.1146/annurev.iy.07.040189.001045

[15] G. T. Seah, G. M. Scott and G. A. Rook, "Type 2 Cytokine Gene Activation and Its Relationship to Extent of Disease in Patients with Tuberculosis," Journal of Infectious Diseases, Vol. 181, No. 1, 2000, pp. 385-389. doi: $10.1086 / 315200$

[16] M. Kopf, G. Le Gros, A. J. Coyle, M. Kosco-Vilbois and F. Brombacher, "Immune Responses of IL-4, IL-5, IL-6 Deficient Mice," Immunological Reviews, Vol. 148, 1995, pp. 45-69. doi:10.1111/j.1600-065X.1995.tb00093.x

[17] K. Shimoda, J. van Deursen, M. Y. Sangster, S. R. Sarawar, R. T. Carson, R. A. Tripp, C. Chu, F. W. Quelle, T. Nosaka, D. A. Vignali, P. C. Doherty, G. Grosveld, W. E. Paul and J. N. Ihle, "Lack of IL-4-Induced Th2 Response and IgE Class Switching in Mice with Disrupted Stat6 Gene," Nature, Vol. 380, No. 6575, 1996, pp. 630-633. doi: $10.1038 / 380630 \mathrm{a} 0$

[18] S. Crotty, "Follicular Helper CD4 T Cells (TFH)," Annual Review of Immunology, Vol. 29, 2011, pp. 621-663. doi:10.1146/annurev-immunol-031210-101400

[19] E. K. Deenick and C. S. Ma, "The Regulation and Role of T Follicular Helper Cells in Immunity," Immunology, Vol. 134, No. 4, 2011, pp. 361-367. doi:10.1111/j.1365-2567.2011.03487.x

[20] Y. Latchman, C. R. Wood, T. Chernova, D. Chaudhary, M. Borde, I. Chernova, Y. Iwai, A. J. Long, J. A. Brown, R. Nunes, E. A. Greenfield, K. Bourque, V. A. Boussiotis, L. L. Carter, B. M. Carreno, N. Malenkovich, H. Nishimura, T. Okazaki, T. Honjo, A. H. Sharpe and G. J. Freeman, "PD-L2 Is a Second Ligand for PD-1 and Inhibits T Cell Activation," Nature Immunology, Vol. 2, No. 3, 2001, pp. 261-268. doi:10.1038/85330

[21] S. M. Mangsbo, L. C. Sandin, K. Anger, A. J. Korman, A. Loskog and T. H. Tötterman, "Enhanced Tumor Eradication by Combining CTLA-4 or PD-1 Blockade with CpG Therapy," Journal of Immunotherapy, Vol. 33, No. 3, 2010, pp. 225-235.

[22] A. H. Sharpe, E. J. Wherry, R. Ahmed and G. J. Freeman, "The Function of Programmed Cell Death 1 and Its Ligands in Regulating Autoimmunity and Infection," Nature Immunology, Vol. 8, No. 3, 2007, pp. 239-245. doi:10.1038/ni1443 
[23] S. Sakai, I. Kawamura, T. Okazaki, K. Tsuchiya, R. Uchiyama and M. Mitsuyama, "PD-1-PD-L1 Pathway Impairs T(h)1 Immune Response in the Late Stage of Infection with Mycobacterium bovis Bacillus CalmetteGuérin," International Immunology, Vol. 22, No. 12. pp. 915-925. doi:10.1093/intimm/dxq446

[24] E. Lázár-Molnár, B. Chen, K. A. Sweeney, E. J. Wang, W. Liu, J. Lin, S. A. Porcelli, S. C. Almo, S. G. Nathenson and W. R. Jacobs Jr., "Programmed Death-1 (PD-1)-Deficient Mice Are Extraordinarily Sensitive to Tuberculosis," Proceedings of the National Academy of Sciences USA, Vol. 107, No. 30, 2010, pp. 13402-13407. doi:10.1073/pnas.1007394107

[25] J. O. Jurado, I. B. Alvarez, V. Pasquinelli, G. J. Martínez, M. F. Quiroga, E. Abbate, R. M. Musella, H. E. Chuluyan and V. E. García, "Programmed Death (PD)-1: PD-Ligand 1/PD-Ligand 2 Pathway Inhibits T Cell Effector Functions during Human Tuberculosis," Journal of Immunotherapy, Vol. 181, No. 1, 2008, pp. 116-125.

[26] X. Y. He, J. Li, J. Hao, H. B. Chen, Y. Z. Zhao, X. Y. Huang, K. He, L. Xiao, L. P. Ye, Y. M. Qu and L. H. Ge, "Assessment of Five Antigens from Mycobacterium tuberculosis for Serodiagnosis of Tuberculosis," Clinical and Vaccine Immunology, Vol. 18, No. 4, pp. 565-570. doi:10.1128/CVI.00507-10

[27] S. Banerjee, A. Nandyala, R. Podili, V. M. Katoch, K. J. Murthy and S. E. Hasnain, "Mycobacterium tuberculosis (Mtb) Isocitrate Dehydrogenases Show Strong B Cell Response and Distinguish Vaccinated Controls from TB Patients," Proceedings of the National Academy of Sciences USA, Vol. 101, No. 34, 2004, pp. 12652-12657. doi:10.1073/pnas.0404347101

[28] W. Barcelos, O. A. Martins-Filho, T. M. Guimarães, M. H. Oliveira, S. Spíndola-de-Miranda, B. N. Carvalho and P. Toledo Vde, "Peripheral Blood Mononuclear Cells Immunophenotyping in Pulmonary Tuberculosis Patients before and after Treatment," Microbiology and Immunology, Vol. 50, No. 8, 2006, pp. 597-605.

[29] T. M. Wozniak, B. M. Saunders, A. A. Ryan and W. J. Britton, "Mycobacterium bovis BCG-Specific Th17 Cells Confer Partial Protection against Mycobacterium tuberculosis Infection in the Absence of Gamma Interferon," Infection and Immunity, Vol. 78, No. 10, 2010, pp. 41874194. doi:10.1128/IAI.01392-09

[30] J. Winek, U. Demkow, E. Rowińska-Zakrzewska, M. Szołkowska, M. Filewska, J. Jagodziński and K. Roszkowski-Sliz, "Comparison of Th1 and Th2 Response in the Blood of Tuberculous Patients and Healthy Contacts," Pneumonologia Alergologia Polska, Vol. 77, No. 5, 2009, pp. 446-452.

[31] V. H. Sai Priya, G. S. Latha, S. E. Hasnain, K. J. Murthy and V. L. Valluri, "Enhanced T Cell Responsiveness to Mycobacterium bovis BCG r32-kDa Ag Correlates with Successful Anti-Tuberculosis Treatment in Humans," Cytokine, Vol. 52, No. 3, pp. 190-193.

doi:10.1016/j.cyto.2010.07.001

[32] Y. Tsukamoto, M. Endoh, T. Mukai, Y. Maeda, T. Tamura, M. Kai and M. Makino, "Immunostimulatory Activity of Major Membrane Protein II from Mycobacterium tuberculosis," Clinical and Vaccine Immunology, Vol. 18,
No. 2, 2010, pp. 235-242. doi:10.1128/CVI.00459-10

[33] C. M. Rueda, N. D. Marín, L. F. García and M. Rojas, "Characterization of CD4 and CD8 T Cells Producing IFN- $\gamma$ in Human Latent and Active Tuberculosis," Tuberculosis (Edinburgh), Vol. 90, No. 6, 2010, pp. 346353. doi:10.1016/j.tube.2010.09.003

[34] A. M. Gallegos, J. W. J. van Heijst, M. Samstein, X. Su, E. G. Pamer and M. S. Glickman, "A Gamma Interferon Independent Mechanism of CD4 T Cell Mediated Control of M. tuberculosis Infection in Vivo," PLOS Pathogens, Vol. 7, No. 5, 2011, Article ID: e1002052. doi:10.1371/journal.ppat.1002052

[35] S. C. de Cassan, A. A. Pathan, C. R. Sander, A. Minassian, R. Rowland, A. V. Hill, H. McShane and H. A. Fletcher, "Investigating the Induction of Vaccine-Induced Th17 and Regulatory T Cells in Healthy, Mycobacterium bovis BCG-Immunized Adults Vaccinated with a New Tuberculosis Vaccine, MVA85A," Clinical and Vaccine Immunology, Vol. 17, No. 7, 2010, pp. 1066-1073. doi:10.1128/CVI.00047-10

[36] D. Freches, M. Romano, H. Korf, J. C. Renauld, J. Van Snick, C. Uyttenhove and K. Huygen, "Increased Pulmonary Tumor Necrosis Factor Alpha, Interleukin-6 (IL-6), and IL-17A Responses Compensate for Decreased Gamma Interferon Production in Anti-IL-12 AutovaccineTreated, Mycobacterium bovis BCG-Vaccinated Mice," Clinical and Vaccine Immunology, Vol. 18, No. 1, 2011, pp. 95-104. doi:10.1128/CVI.00352-10

[37] J. I. Basile, L. J. Geffner, M. M. Romero, L. Balboa, Y. García. C. Sabio, V. Ritacco, A. García, M. Cuffré, E. Abbate, B. López, L. Barrera, M. Ambroggi, M. Alemán, M. C. Sasiain and S. S. de la Barrera, "Outbreaks of $M y$ cobacterium tuberculosis MDR Strains Induce High IL-17 T-Cell Response in Patients with MDR Tuberculosis That Is Closely Associated with High Antigen Load,' The Journal of Infectious Diseases, Vol. 204, No. 7, 2011, pp. 1054-1064. doi:10.1093/infdis/jir460

[38] T. Wang, M. Lv, Q. Qian, Y. Nie, L. Yu and Y. Hou, "Increased Frequencies of T Helper Type 17 Cells in Tuberculous Pleural Effusion," Tuberculosis (Edinburgh), Vol. 91, No. 3, 2011, pp. 231-237. doi:10.1016/j.tube.2011.02.002

[39] X. Chen, M. Zhang, M. Liao, M. W. Graner, C. Wu, Q. Yang, H. Liu and B. Zhou, "Reduced Th17 Response in Patients with Tuberculosis Correlates with IL-6R Expression on $\mathrm{CD}^{+}{ }^{+} \mathrm{T}$ Cells," American Journal of Respiratory and Critical Care Medicine, Vol. 181, No. 7, 2009, pp. 734-742. doi:10.1164/rccm.200909-1463OC

[40] A. Kahnert, P. Seiler, M. Stein, S. Bandermann, K. Hahnke, H. Mollenkopf and S. H. Kaufmann, "Alternative Activation Deprives Macrophages of a Coordinated Defense Program to Mycobacterium tuberculosis," European Journal of Immunology, Vol. 36, No. 3, 2006, pp. 631-647. doi:10.1002/eji.200535496

[41] C. S. Hirsch, Z. Toossi, C. Othieno, J. L. Johnson, S. K. Schwander, S. Robertson, R. S. Wallis, K. Edmonds, A. Okwera, R. Mugerwa, P. Peters and J. J. Ellner, "Depressed T-cell Interferon-Gamma Responses in Pulmonary tuberculosis: Analysis of Underlying Mechanisms and Modulation with Therapy," The Journal of Infectious 
Diseases, Vol. 180, No. 6, 1999, pp. 2069-2073. doi:10.1086/315114

[42] C. Lienhardt, A. Azzurri, A. Amedei, K. Fielding, J. Sillah, O. Y. Sow, B. Bah, M. Benagiano, A. Diallo, R. Manetti, K. Manneh, P. Gustafson, S. Bennett, M. M. D'Elios, K. McAdam and G. Del Prete, "Active Tuberculosis in Africa Is Associated with Reduced Th1 and Increased Th2 Activity in Vivo," European Journal of Immunology, Vol. 32, No. 6, 2002, pp. 1605-1613. doi:10.1002/1521-4141(200206)32:6<1605::AID-IMMU $\underline{1605>3.0 . \mathrm{CO} ; 2-6}$

[43] R. J. Al-Attiyah and A. S Mustafa, "Mycobacterial Antigen-Induced T Helper Type 1 (Th1) and Th2 Reactivity of Peripheral Blood Mononuclear Cells from Diabetic and non-Diabetic Tuberculosis Patients and Mycobacterium bovis Bacilli Calmette-Guérin (BCG)-Vaccinated Healthy Subjects," Clinical \& Experimental Immunology, Vol. 158, No. 1, 2009, pp. 64-73. doi:10.1111/j.1365-2249.2009.04000.x

[44] I. B. Alvarez, V. Pasquinelli, J. O. Jurado, E. Abbate, R. M. Musella, S. S. de la Barrera and V. E. García, "Role Played by the Programmed Death-1-Programmed Death Ligand Pathway during Innate Immunity against Mycobacterium tuberculosis," The Journal of Infectious Diseases, Vol. 202, No. 4, 2010, pp. 524-532. doi:10.1086/654932

[45] S. Tousif, Y. Singh, D. V. Prasad, P. Sharma, L. Van Kaer and G. Das, "T cells from Programmed Death-1 Deficient Mice Respond Poorly to Mycobacterium tuberculosis Infection," PLoS One, Vol. 6, No. 5, 2011, Article ID: e19864. doi:10.1371/journal.pone.0019864

[46] D. L. Barber, K. D. Mayer-Barber, C. G. Feng, A. H. Sharpe and A. Sher, "CD4 T Cells Promote Rather than Control Tuberculosis in the Absence of PD-1-Mediated Inhibition," Journal of Immunotherapy, Vol. 186, No. 3,
2010, pp. 1598-1607. doi:10.4049/jimmunol.1003304

[47] F. W. McNab, M. P. Berry, C. M. Graham, S. A. Bloch, T. Oni, K. A. Wilkinson, R. J. Wilkinson, O. M. Kon, J. Banchereau, D. Chaussabel and A. O'Garra, "Programmed Death Ligand 1 Is Over-Expressed by Neutrophils in the Blood of Patients with Active Tuberculosis," European Journal of Immunology, Vol. 41, No. 7, 2011, pp. 1941-1947. doi:10.1002/eji.201141421

[48] H. M. Vordermeier, N. Venkataprasad, D. P. Harris and J. Ivanyi, "Increase in Tuberculous Infection in Organs of B Cell-Deficient Mice," Clinical \& Experimental Immunology, Vol. 106, No. 2, 1996, pp. 312-316. doi:10.1046/j.1365-2249.1996.d01-845.x

[49] P. J. Maglione, J. Xu and J. Chan, "B Cells Moderate Inflammatory Progression and Enhance Bacterial Containment upon Pulmonary Challenge with Mycobacterium tuberculosis," Journal of Immunotherapy, Vol. 178, No. 11, 2007, pp. 7222-7234.

[50] J. Hernandez, C. Velazquez, O. Valenzuela, R. RoblesZepeda, E. Ruiz-Bustos, M. Navarro and GaribayEscobar, "Low Number of Peripheral Blood B Lymphocytes in Patients with Pulmonary Tuberculosis," Immunological Investigations, Vol. 39, No. 3, 2010, pp. 197205. doi:10.3109/08820130903586346

[51] Y. E. Wu, S. W. Zhang, W. G. Peng, K. S. Li, K. Li, J. K Jiang, J. H. Lin and Y. M. Cai, "Changes in Lymphocyte Subsets in the Peripheral Blood of Patients with Active Pulmonary Tuberculosis," Journal of Internal Medicine, Vol. 37, No. 6, 2009, pp. 1742-1749.

[52] E. Aktas, F. Ciftci, S. Bilgic, O. Sezer, E. Bozkanat, O. Deniz, U. Citici and G. Deniz, "Peripheral Immune Response in Pulmonary Tuberculosis," Scandinavian Journal of Immunology, Vol. 70, No. 3, 2009, pp. 300-308. doi:10.1111/j.1365-3083.2009.02294.x 